\title{
El-Nino, La-Nina and Non-Active ENSO Events Relation with Solar Activity in the Perspective of Markov Process
}

Muhammad Fahim Akhter ( $\sim$ m_fahimakhter@yahoo.com )

Mathematical Sciences Research Centre Federal Urdu University of Arts

Shaheen Abbas

Mathematical Sciences Research Centre Federal Urdu University of Arts

Danish Hassan

National Textile University

\section{Research Article}

Keywords: Cl, El-Nino, La-Nino, Transition Matrix, Transition diagram

Posted Date: January 17th, 2022

DOI: https://doi.org/10.21203/rs.3.rs-1205948/v1

License: (c) (i) This work is licensed under a Creative Commons Attribution 4.0 International License.

Read Full License 


\title{
El-Nino, La-Nina and non-active ENSO events relation with solar activity in
} the perspective of Markov process

\author{
Muhammad Fahim Akhter ${ }^{1 *}$, Shaheen Abbas ${ }^{1}$, Danish Hassan ${ }^{2}$ \\ ${ }^{1}$ Mathematical Sciences Research Centre Federal Urdu University of Arts, Sciences and \\ Technology, Karachi, Pakistan \\ ${ }^{2}$ Department of Applied Sciences, National Textile University, Karachi Campus, Karachi, Pakistan \\ m_fahimakhter@yahoo.com, shaheen.abbas@fuuast.edu.pk, danish10ansari@gmail.com
}

\section{Abstract}

Past investigations have been done against the sun powered atmosphere relationship and discovered huge comprehension between them. Our goal is to comprehend the sun based atmosphere progress with the assistance of Markov chain lattices. In that association we utilized solar (CI) and climate(ENSO) dataset from 1950 to 2016. All through the period atmosphere information are conveyed into El Nino, La Nino and non-active(ENSO) occasions and discovered solid connection with related CI information. The critical solid 2-dimensional correlation supported connection between El Nino and non-active(ENSO) with related CI networks (0.9865 and 0.8358$)$ separately. So additionally, both El Nino and non-active(ENSO) with contrasting CI shows the higher number of visits in state 3 while La Nino shows a higher number of visits in state 1. Our examination shows the Markov cycle and embraced the main request Markov chain property for CI, El-Nino, La Nina and Non-active(ENSO) boundaries. The obtained results transitional probabilities of climate events with solar activity may be helpful to understand the future variation of events chances using Markov technique.

\section{Keywords: CI, El-Nino, La-Nino, Transition Matrix, Transition diagram}

\section{Introduction}

The atmosphere development generally relies upon sunlight based variety. The variety of the sun powered cycle may shape the atmosphere occasions like El Nino, La Nino and non-active(ENSO). These occasions are caused outrageous condition like the inconstancy of precipitation, dry seasons and flood fiasco and so forth (Iqbal and Hassan 2018). As indicated by the sun oriented cycle, moderates wind field was untimely in the past in stratosphere and troposphere to the built up connect among ENSO and mathematical effect(Akhter et al. 2019). The straight relationship with respect to sunspot movement from the effect of different components like ENSO and springs of gushing lava and so on clarified by numerous relapse (Brugnara et al. 2013). Further in an examination, it was 
31 discovered that the connection of sunspot cycle with the El-Nino event as far as mean recurrence (5.5 years) is twice 32 of the sunspot cycle (about 11-years) (Cole et al. 2000 and Ruzmaikin 1999). In another investigation (Higginson et 33 al. 2004) likewise explained these two information he clarifies the main and slacking conduct with their 34 periodicities. The sign was that the El-Nino occasions happen 2-3 years after and before the pinnacle of sunspots and normal periodicities generally $50 \%$ of the length of the sun oriented cycle. Markov cycle will be a cutting edge method to comprehend the geophysical cycle. It is a discrete cycle that relies upon temporary probabilities which can be useful to get to future possibilities. Despite the fact that numerous worldwide cycles are examined as a Markov cycle with its chain that speaks to an arrangement of components moving starting with one state then onto the next (Shamshad 2005). In a real-world number of problems follows Markovity because it is a free memory process not dependent on preceding events. The future occurrence of events can be estimated with transition probabilities by present to future events is done by (Akhter et al. 2019). Our study applied Markov process on El-

42 Nino, La-Nina \& non-active ENSO events with solar activity. Individually, the transition of each climate events is checked with solar activity.

44 The paper is consists of four sections in which the first two sections $(1 \& 2)$ depends on the introduction and transitional probability of stochastic Markov process. The methodology consistent for time-dependent variation of events that represents the state of one event depends on the current state, not on the sequence of previous events.

47 These possibilities of events calculated in section 2 along with a maximum number of visits. Section 3 discussed the results of El Nino, La Nino and non-active(ENSO) with CI cyclicity. Finally, section 4 concludes the study.

\section{Data description and Methodology}

\section{$50 \quad 2.1$ Description of ENSO and CI intensities}

51 The study used Co-occurrence of ENSO events with the perspective of CI dataset. The ENSO is the most active for 52 short-term prediction of Earth's climate discussed by Chen and Cane (2008). The ENSO events are classified into 53 two events El-Nino (Warm phase) and La-Nina (Cool phase) in the tropical Pacific. It is the running 3 month mean

54 SST (sea surface temperature) anomaly of Nino 3.4 region $\left(5^{0}-\mathrm{N}-5^{0} \mathrm{~S}, 120^{0}-170^{0}-\mathrm{W}\right)$. The sea surface temperature 55 (SST) anomaly at the western Pacific Ocean is at above $+0.5^{0} \mathrm{C}$ count El-Nino (warm phase) and when SST is 56 below at $-0.5^{0} \mathrm{C}$ said La-Nino (cool Phase) events. These events are (2-7 year period) and take apart for the 57 formation of world climate disturbance (Mahala et al. 2015; Chang et al. 2006). The secondary dataset based on CI 
(corresponding of El-Nino, La-Nina \& non-active ENSO) dataset for the range of 1950 to 2016 is taken from the

National Oceanic and Atmospheric Administration (NOAA) (http ://www.cpc.noaa .gov/products /analysis

61 graph of CI-El-Nino, CI-La-Nina and CI-nonactive(ENSO) depicted in Fig 1(a, b \& c).

62

Fig.1(a): comparison of La-

Nina and associated

CI time series.

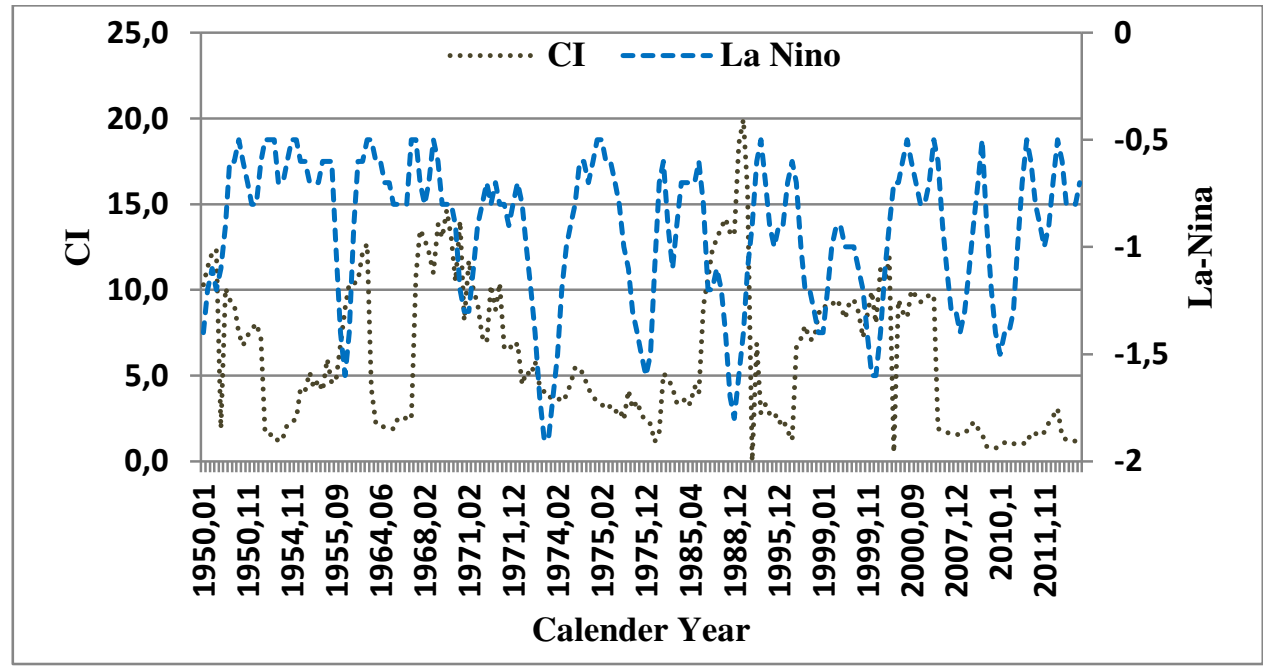

63

Fig. 1(b): comparison of ElNino and associated CI time series.

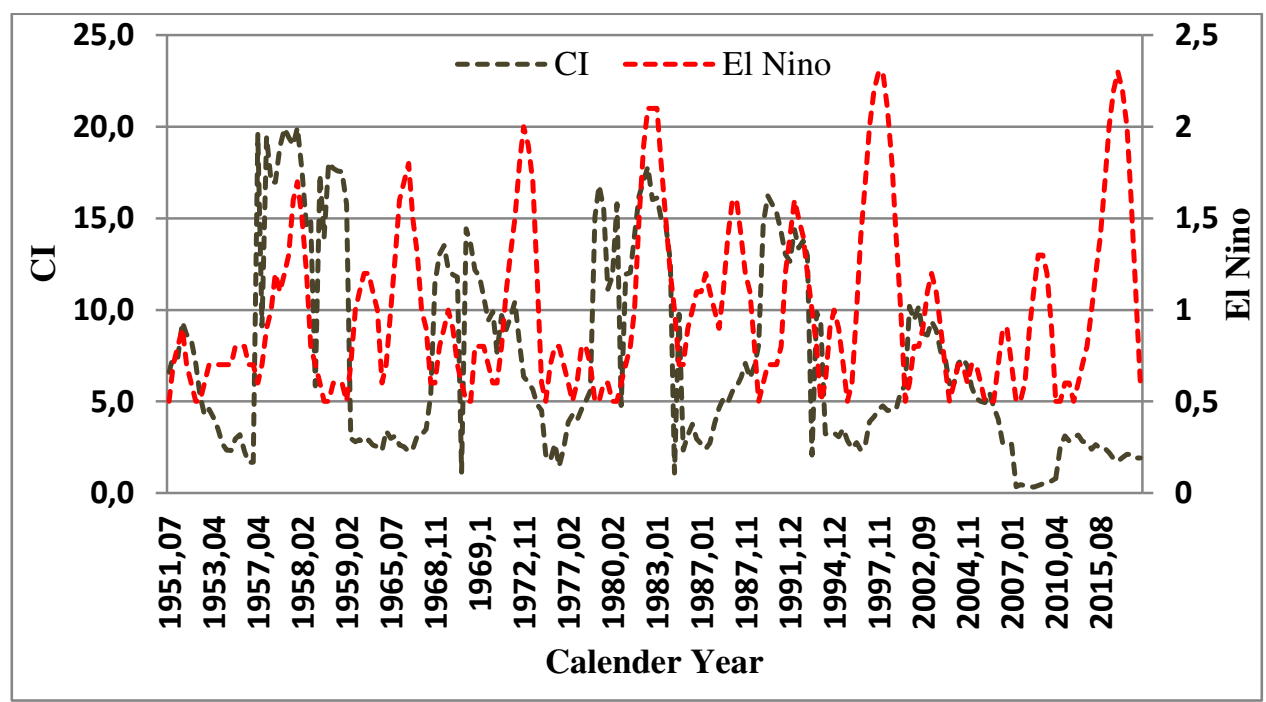


Fig.1(c): comparison of nonactive(ENSO) and associated CI time series.
67

68

69

70

71

72

73

74

75

76

77

78

79

80

81

82

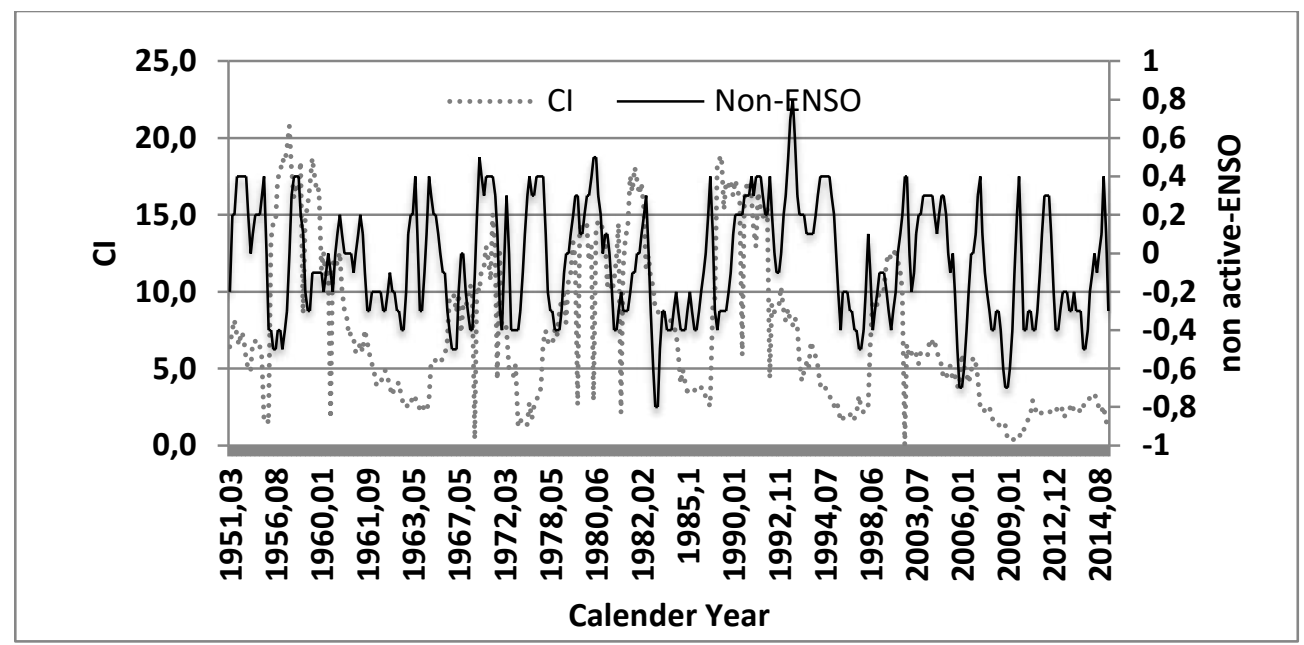

\subsection{Methodology}

2.2.1 Formation (transition probability matrices) of extreme events and CI intensities

By the use of Markov chain transition probability matrices are formed on ENSO and CI data from 1950 to 2016. The ENSO data consists of La-Nina, El-Nino, and Non-active ENSO events. We used El-Nino and La-Nina data events in the range from 1950 to 2016 along with corresponding CI data. The threshold of events broken into Weak (0.5 to 0.9 SST anomaly), Moderate (1.0 to 1.4$)$, strong (1.5 to 1.9$)$ and very strong ( $>=2.0$ )events are considered as standard (http://ggwe at the r.com/enso /oni.htm). The time-series graph of El-Nino(Red) and La-Nina(blue) is presented in Fig 2. In our study, we formed above-broken events into three intervals (states) weak, moderate, and strong for El-Nino, La-Nino and non-active(ENSO) events. We found the range of each event and divides these ranges into three equal interval called states. These intervals are transition probabilities or transition states. Which is a better way to understand the effect of CI on El-Nino, La-Nina and non-active (ENSO) because Markov technique provides future occurrence of events probability on behalf of current event probability without using preceding events (Akhter et al. 2019; Iqbal and Hassan 2018). The three-state classification of La-Nina, El-Nino and nonactive ENSO corresponding $\mathrm{CI}$ is defined below as 


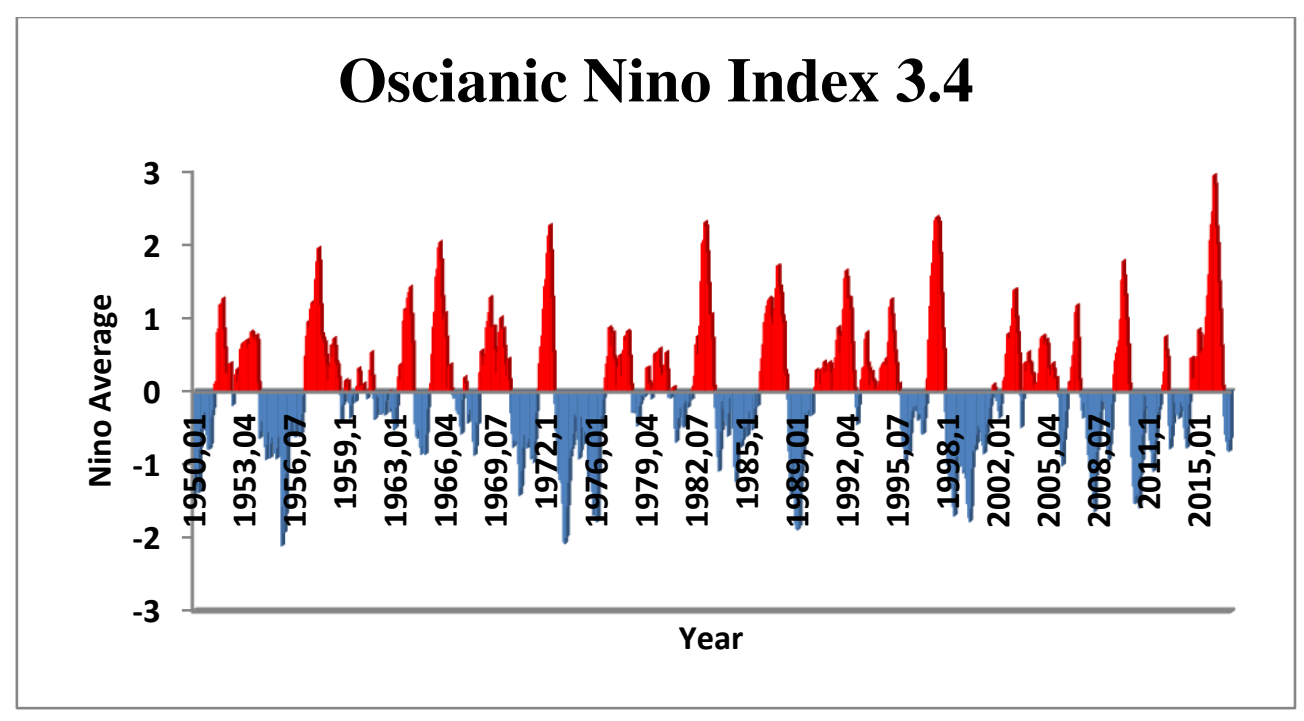

Fig. 2 Time series plot of El-Nino(Red) and La-Nina(Blue) from 1950 to 2016

85

State $1 \longrightarrow$ Weak

87 State $3 \rightleftharpoons$ Strong

$\underline{1950-2016}$

La-Nina:State 1 (-0.5 to -0.96$)$, State 2(-0.96 to -1.43$)$, State 3(-1.43 to -1.9$)$

90

CI: State 1(0.5-6.99), State 2(6.99-13.47), State 3(13.47-19.96)

91 El-Nino: State 1(0.5-1.1), State 2(1.1-1.7), State 3(1.7-2.3)

92 CI: State 1(0.32-6.86), State 2(6.86-13.41), State 3(13.41-19.96)

non-ENSO: State1(-0.8 to -0.3$)$, State 2(-0.3 to 0.3$)$, State 3(0.3-0.8)

94 CI: State1(0.02-6.94), State 2(6.94-13.87), State 3(13.87-20.79)

\subsubsection{Markov Chains}

96 A Markov chain process is a simple type of stochastic process that communicates with changes of the state over the

97 discrete-time step is called a Markov chain. The first-order Markov chain depends only on the immediately

98 preseeding one. Using of first-order chain $\mathrm{K}$ states $\mathrm{S}=\{1,2, \ldots, \mathrm{k}\}$ satisfying the following probabilities

$$
P\left(x_{t+1}=i_{t+1} \mid x_{0}=i_{0}=, \ldots, x_{t}=i_{t}\right)=P\left(x_{t+1}=i_{t+1} \mid x_{t}=i_{t}\right)
$$

Where $\mathrm{x}_{\mathrm{t}}$ denotes the state of stochastic time series process (Shamshad et al. 2005) 
Let $\mathrm{X}(\mathrm{t})$ be a sequence over given time points $t_{1}<t_{2}<\ldots<t_{n-1}$, then the conditional probability is defined as

$$
P\left\{x\left(t_{n}\right)=i_{n} \mid x\left(t_{1}\right)=i_{1}, \ldots, x\left(t_{n-1}\right)=i_{n-1}\right\}=P\left\{x\left(t_{n}\right)=i_{n} \mid x\left(t_{n-1}\right)=i_{t}\right\}
$$

101 These conditional probabilities are called transition probabilities such that $\mathrm{P}\{\mathrm{x}(\mathrm{t})=\mathrm{j} \mid \mathrm{x}(\mathrm{d})=i\}=P_{i j}(d, t)$, where 102 transition order $r=t-d$ from state $i$ to state $j$ for all $0 \leq d<t$ with $i \geq 1$ and $j \leq k$.(Akhter et al. 2016; Iqbal \& Hassan, 2017)

\subsubsection{Formation of transition probability matrices}

104 The process of Markov chain may be summarized in the transition matrix as

$$
P=\left[\begin{array}{cccc}
P(1,1) & P(1,2) & \ldots & P(1, n) \\
P(2,1) & P(2,2) & \ldots & P(2, n) \\
\vdots & \vdots & \ddots & \vdots \\
P(n, 1) & P(n, 2) & \ldots & P(n, n)
\end{array}\right]
$$

Where entries of transition matrix are conditional probabilities may be estimated by relative frequency and written as

$$
\begin{gathered}
P(i, j)=\frac{n_{i j}}{\Sigma_{j} n_{i j}} \\
P(i, j) \geq 0 \text { for all } i, j \in S .
\end{gathered}
$$

Further probability of entire row must be a probability vector, whose sum 1 such that

$$
\sum_{j \in S} P(i, j)=1 \text { for all } i \in S \text {. }
$$

Table 1(a). Transition matrices of La-Nina, El-Nino and Non-active ENSO with associated CI

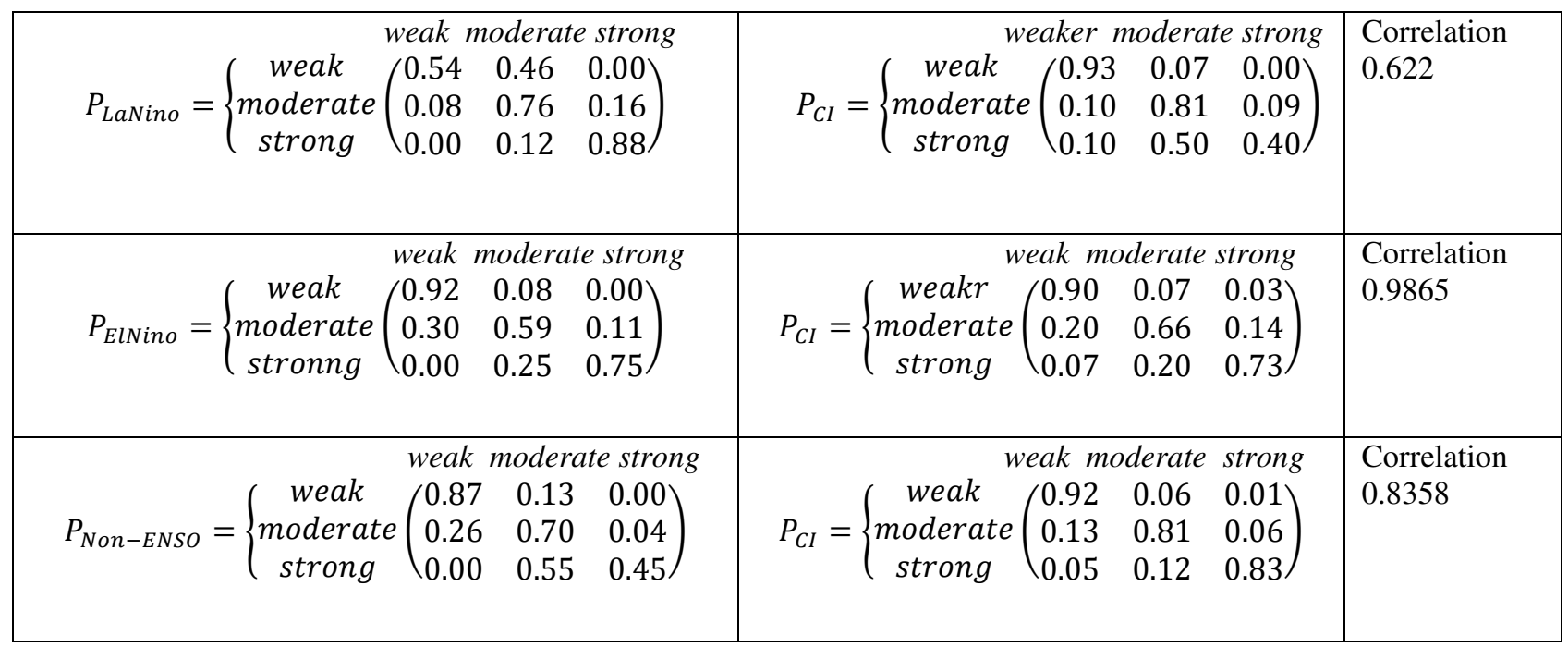


Table. 1(b) Transition diagram of El-Nino, La-Nina and NOn-Enso with related CI.

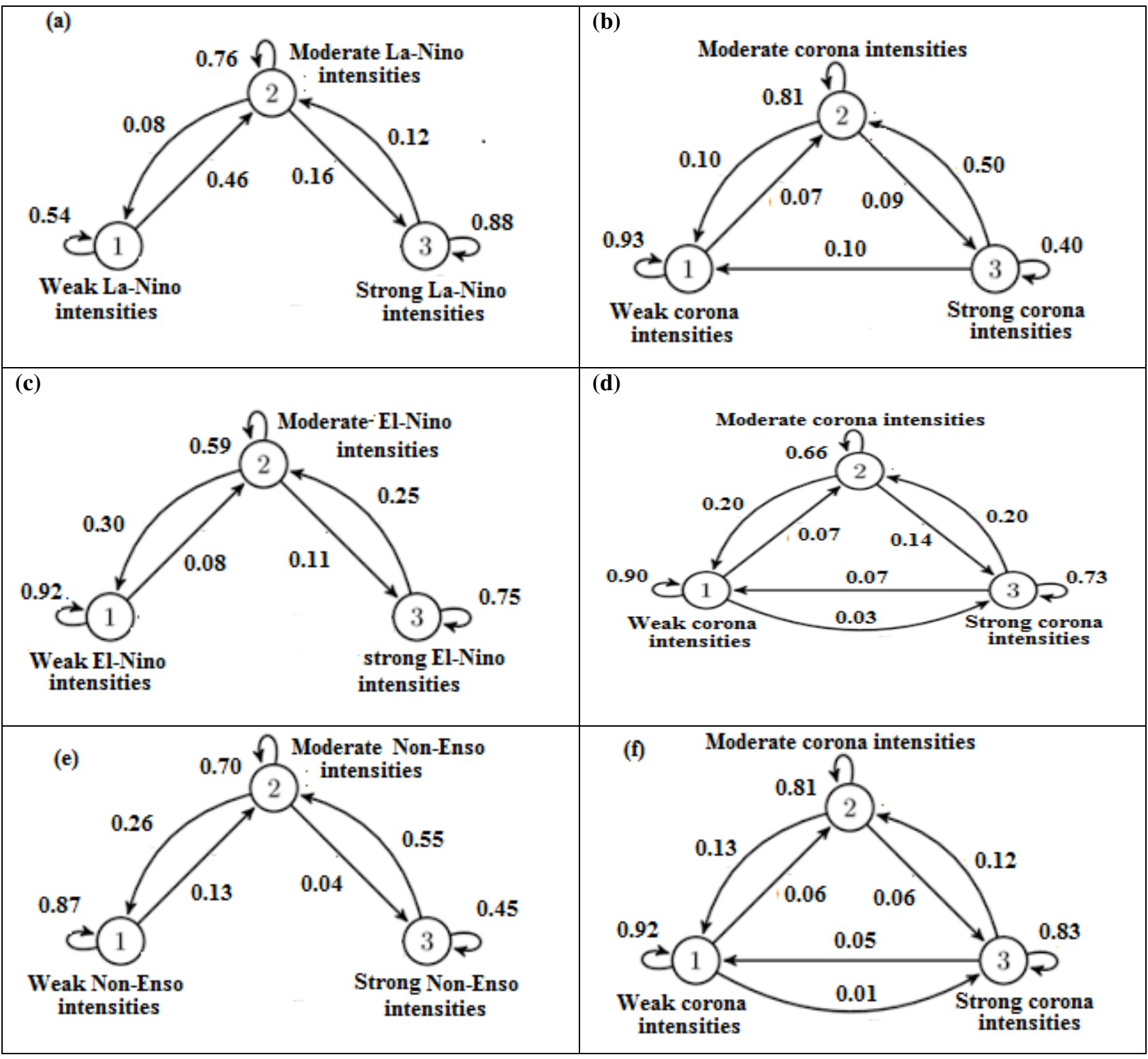

\subsubsection{Expected number of visits}

118 The two states recall same communication class as an endpoint of the first state is connected with the initial point of

119 the second state. Similarly, all states communicate with each other and have one communication class is known as 120 an irreducible matrix (Brown and Ross 1969). The irreducible matrix technique is used to find the number of steps

121 for any state visits in the chain. If in any chain a state visit only states $i$ infinite times, then state $i$ is said to be 122 transient with probability 1. A Markov chain never leaves from the recurring class with initiating a recurring from 123 that class (Lawler 2004). Let Markov chain $X_{n}$ contain a transition matrix $\boldsymbol{P}$. The matrix $\boldsymbol{P}$ recalls a state ' $i$ ' is called 
124 a transient with probability 1, the chain visits only ' $i$ ' finite number of times. The transition matrix $\boldsymbol{P}$ (after 125 rearranging the order of the states) can be written as

$$
P=\left[\begin{array}{ll}
\bar{p} & 0 \\
S & Q
\end{array}\right]
$$

127 Where $Q$ is a transient sub-matrix of $P$, containing rows and columns for transient states.

128 In reducible Markov chain, there is at least one recurrent class $(\overline{\boldsymbol{p}})$ of the matrix, $\mathrm{P}$, that contains only rows and 129 columns for states in $\overline{\boldsymbol{p}}$. Hence $I-Q$ is an invertible matrix and the expected number of visits from 'i' to ' $\boldsymbol{j}$ ' is denoted $130 \quad$ by $\boldsymbol{M}_{j i}$. Where invertible matrix $\boldsymbol{M}$ is written as

$$
M=(I-Q)^{-I}
$$

132 The transient state is the expected number of steps until the chain enters a recurring class $\left(\right.$ such that $\left.\mathrm{X}_{0}=j\right)$. This 133 approach can be used for irreducible Markov chain (Akhter et al. 2019; Hassan et al. 2016; Lawler 2004; Iqbal \& 134 Hassan, 2018).

\subsection{5 validity of the Markov chain}

137 The validity of the Markov chain method for El-Nino and La-Nina is tested by the following properties using 138 statistic $\alpha$ and $\beta$ test.

\section{$139 \quad$ 2.2.5.1 State dependency test}

140 State dependency of Markov chain confirms the existence of the Markov method (Torre et al. 2001; Logofet and

141 Lensnaya 2000). The Markov chain properties describe whether the successive events are independent or dependent

142 on each other. For successive events independence check by statistic $\alpha$, the statistic is distributed asymptotically as $143 \chi^{2}$ having $(k-1)^{2}$ degree of freedom (DF), where $k$ is the total number of states.

144 The statistic $\alpha$ is written as

$$
\alpha=2 \sum_{i, j}^{k} n_{i j} \ln \frac{P_{i j}}{P_{j}} \quad \quad \quad \quad \quad \quad p_{j}=\frac{\sum_{i}^{m} n_{i j}}{\sum_{i, j}^{m} n_{i j}}
$$

146 where $p_{j}$ represents the marginal probability of $j$ th column of transition matrix and $n_{i j}$ is the frequency in state $i$ 147 followed by state $j$. 
In this paper, the test applied on whole data series and divided the ENSO data with associated CI data into three intervals, La-Nina, El-Nino and Non-ENSO. According to (Liu 2010) the null hypothesis successive transition is independent is rejected when the statistic $\alpha$ is greater than $\chi^{2}\left(\alpha>\chi^{2}\right)$ under a $5 \%$ level of significance. The values of $\alpha$ are observed higher in all cases than $\chi^{2}$ value of 9.488 at $5 \%$ level with 4 degrees of freedom. Thus the null

152 hypothesis of successive transitions are independent is rejected. The values of test statistic $\alpha$ of both ENSO and CI for the first-order Markov chain demonstrated in Table 2.

Table 2.The value of $\alpha$ for each ENSO events with CI

\begin{tabular}{|l|l|r|}
\hline \multirow{2}{*}{ Data series } & \multicolumn{2}{|l|}{ Value of $\alpha$} \\
\cline { 2 - 3 } & CI & \multicolumn{1}{|c|}{ ENSO } \\
\hline $1950-2016$ & 1516.311 & 818.0859 \\
\hline La-Nina & 166.029 & 142.4335 \\
\hline El-Nino & 323.9428 & 151.4974 \\
\hline non-ENSO & 764.2973 & 214.9655 \\
\hline
\end{tabular}

Based on hypothesis concludes the transition of ENSO and CI has first-order Markov chain property.

\subsubsection{Temporal Stationary}

159 Markov process is said to be stationary if transition matrix probabilities do not depend on time. The stationary of matrices is checked by statistics $\beta$ when matrices are approximately equal to each other. The statistic $\beta$ defined below

$162 \quad \beta=2 \sum_{1}^{T} \sum_{i, j}^{k} n_{i j}(t) \ln \left[\frac{P_{i j(t)}}{p_{i j}}\right]$

163 Where

$164 \quad T \quad$ represents the number of time intervals

$165 P_{i j}(\mathrm{t}) \quad$ transition probabilities for the $t$ th intervals of time

$166 n_{\mathrm{ij}}(\mathrm{t}) \quad$ matrix frequencies for $t$ th interval of time

167 The Markov chain is stationary if $\beta<\chi^{2}$ having a degree of freedom $k(k-1)(T-1)$ and the statistic $\beta$ have $\chi^{2}$

168 distribution at 5\% level of significance (Shamshad et al. 2005). 


\section{Results and Discussion}

172 The findings of this research work based on Markov transition matrices, that uses(CI with El-Nino, La-Nina \& non173 active ENSO) monthly dataset from 1950 to 2016. The datasets are distributed in La-Nina, El-Nino and non-active 174 ENSO events and associated CI distributed on the same respect. We observed 67 years (804 months) anomalies data 175 taken in which 220 El-Nino and 198 La-Nina data points while the remaining 386 are non-active ENSO. Further, 176 these events are distributed into three equal states, the namely weak, moderate and strong formation of states defined 177 in (Sec 2.2.1). Using transition matrices of each row sum 1 (e.g., stochastic matrix) observed. Each matrix row was represented present events and the column was the future state transition probabilities. By transition matrices and transition diagram, we can observe the incoming and outgoing transition states probabilities. For example transition of the present (weak events) shifts into future (moderate events) has a $46 \%$ chance for El-Nino matrix and similar vice versa for other states of ENSO events can be seen in Table 1(a) and 1(b). The transition matrices of each ElNino, La-Nina and non-active(ENSO) with the corresponding CI furnished in Table 1(a). In a comparison of transition matrices (El-Nino, La-Nina \& non-active ENSO) with associated CI showed the higher transition probability occurred in the main diagonal. This indication represents periodic behaviour in both the data sets. Moreover, higher diagonal probabilities represent strong self-communication in study matrices. The flow of moving states one state to another are designed in Table 1(b). The connectivity of matrices determines by 2-Dimensional correlation. Warm phase El-Nino with associated CI showed strong 2-Dimensional correlation (0.9865), while the 2Dimensional correlation between cold phase La-Nina matrix with associated CI is relatively strong (0.622). Similarly, non-active ENSO with CI showed strong two-dimension correlation(0.8358). Further related ENSO events with corresponding CI time-series graph demonstrated in Fig.1(a,b,c). We can obtain transition states occurrence together by the plotted graph. We have obtained a strong 2-Dimensional correlation between El-Nino and La-Nino with CI transition matrices. Fig.1(b) shows mostly El-Nino +0.5 weak state to $>2$ strong state years are occurred above the 5 unit intensities of CI energy. It means El-Nino events are more active during CI cycles in state 2(moderate) \& state 3(strong). According to Fig.1(a) mostly CI intensities are found below 10 units which are representing state $1 \& 2$ (including half of CI cycle). The meaning is that La-Nina states were more active when CI states in weak and moderate phase. In-case of the non-active(ENSO) events were noted when mostly CI cycle in state $2 \&$ half of cycle in state 3 was active can be observed in Fig.1(c). The work second the Higginson study, he stated that El-Nino events occur before and after the peak of the solar cycle while La- Nina occurs in initial and 
ending phase of CI cycle. In the second phase of the study, we checked the validity of the Markov chain method can be observed in (Sec. 2.2.5). According to state dependency, Markov property was satisfied with using intervals, discussed in (Sec. 2.2.5.1). Similarly stationary condition $\left(\beta<\chi^{2}\right)$ are given in (Sec 2.2.5.2), evaluated stationary values of $\beta_{\text {EINino }}(22.61229)$ and $\beta_{\text {LaNino }}$ (17.46724) of ENSO are smaller than their Chi-squared values $\chi^{2}$ EINino $(188)$ and $\chi^{2}$ LaNino (21.8), respectively. Further associated CI stationary values for both ENSO matrices $\beta C I_{\text {EINino }}(3.57486)$ and $\beta C I_{\text {LaNino }}(9.307688)$ are also smaller than Chi-squared value $\chi^{2} C I_{\text {EINino }}(185)$ and $\chi^{2} C I_{\text {LaNino }}(190)$, respectively. In non-active(ENSO) matrices also show temporal stationery the evaluated stationary value of $\beta_{\text {non-ENSO }}(5.054659)$ is smaller than $\chi^{2} C I_{\text {non-ENSo }}(470)$ value. These results confirmed the validity of the Markov process in our study.

Further, using communication of states recalling (expected number of visits) in the chain (monthly \& yearly) are calculated by the irreducible matrix technique. The result shows El-Nino has an increasing number of visits from lower states $(1 \& 2)$ to a higher state 3 , while lower visits observed in vice-versa. A similar number of visits observed in corresponding CI states, in the earlier section strongest 2-Dimensional correlation (0.9) between CI-ElNino is preserved this number of visits depicts in Table 3(a).

Table 3 (a) Maximum number of Visits El-Nino-CI events (monthly \& yearly), represents by bold size

\begin{tabular}{|c|r|r|r|r|}
\hline $\begin{array}{c}\text { Transition }(\rightarrow) \text { steps } \\
\text { reference to following }\end{array}$ & \multicolumn{2}{|c|}{ No. of steps (monthly) } & \multicolumn{2}{c|}{ No. of Steps (yearly) } \\
\hline $1 \rightarrow 2$ & 12.5 & 12.0478 & 1.041667 & 1.003983 \\
\hline $1 \rightarrow 3$ & $\mathbf{5 5 . 6 8 1 9}$ & $\mathbf{2 0 . 5}$ & 4.640158 & 1.708333 \\
\hline $2 \rightarrow 1$ & 4.8 & 6.4264 & 0.4 & 0.535533 \\
\hline $2 \rightarrow 3$ & $\mathbf{4 3 . 1 8 1 9}$ & $\mathbf{1 5}$ & 3.598492 & 1.25 \\
\hline $3 \rightarrow 1$ & 8.8 & 8.464 & 0.733333 & 0.705333 \\
\hline $3 \rightarrow 2$ & 4 & 6.8273 & 0.33333 & 0.568942 \\
\hline
\end{tabular}

214 The La-Nina events show a reverse number of visits between La-Nina and associated CI states. A higher number of 215 visits are noted from states $(2 \& 3)$ to state 1 , while associated CI shows a maximum number of visits from the lower state $(1 \& 2)$ to higher state 3 . This change of transition also proves low 2-Dimension correlation (0.6) than remaining events(EL-Lino \& non-active(ENSO)). The visits comparison of La-Nina-CI depicted in Table 3(b).

Table 3(b) Maximum number of Visits La-Nina-CI events (monthly \& yearly), represented by the bold size

\begin{tabular}{|c|r|r|r|r|}
\hline $\begin{array}{c}\text { Transition }(\rightarrow) \text { steps } \\
\text { reference to following }\end{array}$ & \multicolumn{2}{|c|}{ No. of steps (monthly) } & \multicolumn{2}{c|}{ No. of Steps (yearly) } \\
\hline $1 \rightarrow 2$ & 2.1739 & 14.286 & 0.181158 & CI \\
\hline $1 \rightarrow 3$ & 9.5109 & $\mathbf{4 1 . 2 7}$ & 0 & 3.4391605 \\
\hline
\end{tabular}




\begin{tabular}{|r|r|r|r|r|}
\hline $2 \rightarrow 1$ & $\mathbf{2 9 . 1 6 7}$ & 9.5109 & 2.430583 & 0.792575 \\
\hline $2 \rightarrow 3$ & 7.337 & $\mathbf{2 6 . 9 8 4}$ & 0.611417 & 2.248667 \\
\hline $3 \rightarrow 1$ & $\mathbf{3 7 . 5}$ & 7.337 & 0 & 0.611417 \\
\hline $3 \rightarrow 2$ & 8.3333 & 4.0477 & 0.694442 & 0.337308 \\
\hline
\end{tabular}

For Non-active(ENSO)-CI return periods describes the maximum expected number of visits from reference state (1

$221 \& 2)$ to 3 observed and reverse vice-versa depicted in Table 3(c). Since a maximum number of visits pattern

222 between $\mathrm{CI}$ and non-active(ENSO) preserved the strong 2-dimensional correlation(0.8) that described in the earlier 223 section.

224 225

Table 3(c) Maximum number of Visits non-active(ENSO)-CI events (monthly \& yearly), represented by the bold size

\begin{tabular}{|c|r|r|r|r|}
\hline $\begin{array}{c}\text { Transition }(\rightarrow) \text { steps } \\
\text { reference to following }\end{array}$ & \multicolumn{2}{|c|}{ No. of steps (monthly) } & \multicolumn{2}{c|}{ No. of Steps (yearly) } \\
\hline $1 \rightarrow 2$ & 7.6923 & 13.74036 & 0.641025 & 1.14503 \\
\hline $1 \rightarrow 3$ & $\mathbf{8 2 . 6 9 2}$ & $\mathbf{3 3 . 7 8 4 1}$ & 6.891 & 2.815342 \\
\hline $2 \rightarrow 1$ & 4.06896 & 9.1633 & 0.33908 & 0.762608 \\
\hline $2 \rightarrow 3$ & $\mathbf{7 5}$ & $\mathbf{2 8 . 3 7 9}$ & 6.25 & 2.364917 \\
\hline $3 \rightarrow 1$ & 5.5173 & 12.3506 & 0.459775 & 1.029217 \\
\hline $3 \rightarrow 2$ & 1.8182 & 9.9237 & 0.151517 & 0.826975 \\
\hline
\end{tabular}

The number of visits comparison for ENSO events with CI solar activity represents El-Nino-CI and nonactive(ENSO)-CI has the same pattern of increasing from reference state to following state $(1 \rightarrow 3 \& 2 \rightarrow 3$ ). Although, La-Nina's with CI indicates an inverse number visits pattern. Reference transition state was move greater state $(2 \& 3)$ to lower state 1 . While CI followed a maximum number of visits from smaller states $(1 \& 2)$ to greater state 3.

\section{Conclusion}

A Markov chain method utilized first-order Markov transition matrices for (EL-Nino's, La-Nina's, \& nonactive(ENSO) with $\mathrm{CI}$ ) and transition from one state to another state over time observed. The number of time steps the transition of (incoming \& outgoing) states. Further, the expected number of visits describes the same pattern of steps increasing in El-Nino, non-active(ENSO) with CI data, meaning is that when cycle increasing (middle and peak phase) then these events noticed more active. The reverse number of steps increasing observed in La-Nina-CI data. Meaning is that when transitions of CI energy states below 10 unit intensities than La Nino phase was more active and most events chances to occur in state 1 observed in the starting and ending phase of the CI cycle. 
However, the strong 2-Dimensional correlation of CI-ENSO matrices, their transition diagrams and applicability

241 (dependency \& stationary) determined the Markov process in this study. Based on the above discussion, solar

242 activity endorsed a part in the extreme ENSO events variation using Markov transition.

243 Acknowledgement

244 This work is a part of first author dessertation. The authors are thankful for NOAA to providing data and first author

245 dedicated to this research work for my late father (Muhammad Akhter Ahmed).

246 Conflict of Interest: No Conflict of interest.

247 Funding Statement: No Funding

248 Author's Contribution: M.F. Akhter conceptualized,methodology and original draft. Shaheen Abbas supervised 249 and Danish Hassan provide assistance.

250 Corresponding author: Muhammad Fahim Akhter

251 Availability of data and material: http ://www.cpc.noaa .gov/products /analysis monitoring/enso stuff/ONI_chan 252 ge.shtml \& https://www.ngdc.noaa.gov/stp/solar/corona.html

253 Code availability: No custom code was used

254 Ethics approval: The research designed on ethical background.

255 Consent to participate: All autor's shown their consent.

256 Consent for publication: Autors are agree for publication.

257 References

258 Akhter MF, Abbas S, Hassan D (2019) The relationship of periodic behaviour between coronal index cycles and 259 associated ENSO by using Markov process. Astrophys Space Sci 364(7): 107:1-9

260 Brown M, Ross SM (1969) Some results for infinite server Poisson queues. Journal of Appl Probab 6:604-611

261 BrugnaraY, Brönnimann S, Luterbacher J, Rozanov E(2013) Influence of the sunspot cycle on the Northern

262 Hemisphere winter time circulation from long upper-airdatasets. Atmos Chem Phys 13:6275

263 Chang P et al (2006) Climate fluctuations of tropical coupled systems-the role of ocean dynamics. J Clim 19:5122$264 \quad 5174$

265 Chen D, Cane MA (2008) El Niño prediction and predictability. J Comput Phys 227:3625-3640

266 Cole J E, Dunbar RB, McClanahan TR, Muthiga NA (2000) Tropical pacific for- cing of decadal SST variability 267 in the western Indian Ocean over the past two centuries. Science 287:617-619. 
268 Hassan D, Iqbal A, Hassan SA, Abbas S, Ansari MRK (2016) Sunspots and ENSO relationship using Markov

269 method. J Atmos Solar Terr Phys 137:53-57

270 Higginson M J, Altabet M, Wincze A, Herbert L, Murray DW T D (2004) A solar (irradiance) trigger for millennial-

271 scale abrupt changes in the southwest monsoon. Paleoceanography 19, PA3015. http://dx.doi.org/10.1029/

$272 \quad$ 2004PA001031

273 Iqbal A, \& Hassan S A (2018) ENSO and IOD analysis on the occurrence of floods in Pakistan. Natural 274 Hazards 91(3): 879-890

275 Lawler GF (2004) An introduction to the stochastic Loewner evolution Random Walks and Geometry 261. Berlin, 276 de Gruyter Co.

277 Liu T (2010) Application of Markov chains to analyze and predict the time series. Mod. Appl. Sci. 4 (5): 162

278 Logofet DO, Lesnaya EV (2000) The mathematics of Markov models: what Markov chains can really predict in 279 forest successions. Ecol Model 126:285-298

280 Mahala BK, Nayak BK, Mohanty PK (2015) Impacts of ENSO and IOD on tropical cyclone activity in the Bay of

281 Bengal. Nat Hazards 75:1105-1125. http ://www.math .corn ell.edu/lawl er/pape rs.html

282 Ruzmaikin A (1999) Can EINino amplify the solar forcing of climate.Geophys Res Lett 26:2255-2259

283 Shamshad A, Bawadi M, Hussin WW, Majid T, Sanusi S (2005) First and second order Markov chain models for 284 synthetic generation of wind speed time series. Energy 30:693-708

285 Torre M, Poggi P, Louche A (2001) Markovian model for studying wind speed time series in Corsica. Int J Renew 286 Energy Eng 3:311-319 